\title{
The functional and radiological comparison of the surgical treatment results of forearm diaphyseal fractures in adults treated with open reduction internal fixation and intramedullary locking nail
}

\author{
Nazan Çevik®, Yavuz Akalın $\odot$, Alpaslan Öztürk๑ \\ Department of Orthopaedics and Traumatology, University of Health Sciences, Bursa Yüksek İhtisas Training and Research Hospital, \\ Bursa, Turkey
}

\section{ABSTRACT \\ Objectives: The results of two different methods applied in the surgical treatment of forearm fractures in adults were evaluated.}

Methods: Thirty-nine patients who applied to our clinic between 2016-2018 and were treated surgically were included in the study. Twenty-three patients out of these were treated with plate osteosynthesis (group 1), and 16 patients were treated with intramedullary locking nail (group 2). While 14 of the patients in group 1 were male, 9 were female, and the average age was 39.8 years (range; 19-74 years); and 11 of the patients in group 2 were male, 5 were female, and the average age was 36.6 years (range; 18-68 years). Patients were called for monthly check-ups until fracture union. Then, radiographic evaluation was done at 3,6 and 12 months. The average follow-up time was 26 months (range;12-36 months) for group 1 and 25 months (range;12-35 months) for group 2. The loss of the line of fracture through radiographic imaging of trabeculations or callus formation in the cortex on the anteroposterior and lateral radiographs, and clinically loss of sensitivity on fracture were considered fracture union. In the last controls, while the elbow was at 90 degrees of flexion, the amount of rotation of both forearms was measured by using the goniometer. In the functional evaluation, the system described by Grace and Eversmann and used to evaluate fracture union and forearm rotation was used. Patient satisfaction was evaluated by using the DASH (Disabilities of the Arm, Shoulder and Hand) method.

Results: While the union duration in group 1 was 12.3 weeks (range; 8-18 weeks), the union duration in group 2 was 12 weeks (range; 9-16 weeks). There was no statistical difference in terms of union durations $(p>0.05)$. In Group 1, according to the Grace-Eversmann evaluation, $19(82.6 \%)$ patients had excellent and good results, three $(13.1 \%)$ patients had acceptable results, and $1(4.3 \%)$ patient had poor results. Forearm pronation of the patient with poor results was less than $60 \%$ but his bone union was complete. In group 1, the average DASH score was 15.04 (range; 3-28). In group 2, Grace-Eversmann evaluation showed excellent and good results in $13(81.3 \%)$ patients and acceptable results in $3(18.7 \%)$ patients. Average DASH score was found to be 14.6 (range; 2-34). When Grace-Eversmann criteria and DASH values were compared, no significant difference was found between the two groups $(p>0.05)$. Vascular nerve injury, tendon injury, radioulnar synostosis, and compartment syndrome were not observed in any patient.

Conclusions: The results of the two fixation methods in terms of functional recovery and patient satisfaction fractures in adults treated with open reduction internal fixation and intramedullary locking nail. Eur Res J 2020;6(5):500-507. DOI: 10.18621/eurj.694212

Address for correspondence: Nazan Çevik., MD, Bursa Yüksek İhtisas Training and Research Hospital, Department of Orthopaedics and Traumatology, Ylldırım,16310,Bursa,Turkey.E-mail: hasanari03@yahoo.com 
were similar in the surgical treatment of forearm double fractures in adults.

Keywords: Adult, forearm diaphyseal fractures, intramedullary locking nail, plate osteosynthesis

T he aim of the treatment of forearm diaphyseal fractures in adults is to provide axial and rotational stability [1]. Due to its functional and anatomical features, forearm diaphyseal fractures are different from long bone diaphyseal fractures, they should be evaluated as intra-articular fractures and treatment planning should be done accordingly [2]. The deforming muscle strength, continuity of the radial slope, and intraosseous membrane damage are important factors affecting the stability and reduction continuity. Open reduction and rigid internal fixation with plate-screw have been suggested by many authors. However, this technique has disadvantages such as causing soft tissue damage, damaging the periosteal circulation due to the discharge of the broken hematoma and plate compression, especially irritating the skin around the ulna [3]. Another disadvantage of the technique is that the fracture is seen again between the rates of $11 \%$ and $20 \%$ after plate removal [4]. The method of fixation with intramedullary unlocking nail causes less soft tissue damage and does not impair the extramedullary blood circulation; however, it may be inadequate to control rotational stability, especially in segmental and segmented fractures.However, intra-canal implants share the load on the bone and provide the formation of peripheral periosteal callus. The superiority of intramedullary locking nail that it can prevent shortcomings that may occur in diaphyseal fractures of the forearm fragments, segmental fractures and metaphysio-diaphyseal fractures [5]. In this study, the results obtained from patients with open reduction and plate-screw fixation, and from patients with closed reduction and intramedullary locking nailwere compared retrospectively.

\section{METHODS}

Thirty-nine patients who applied to our clinic between 2016-2018 and were treated surgically were included in the study. Patient's medical information and demographic distribution are shown in Table 1.
Twenty-three patients out of these were treated with plate osteosynthesis (group 1), and 16 patients were treated with intramedullary locking nail (group 2). While 14 of the patients in group 1 were male, 9 were female, and the average age was 39.8 years (range; 1974 years); and 11 of the patients in group 2 were male, 5 were female, and the average age was 36.6 years (range; 18-68 years). In the fractures classified according to $\mathrm{AO}$ classification, 10 patients were type $\mathrm{A}, 8$ patients were type B, 5 patients were type $C$ in group 1. In Group 2, 8 patients were type $A, 5$ patients were type B, 3 patients were type C. Patients with additional injuries, pathological fractures, open fractures, and patients without pineal plate were excluded. Patients were called for monthly check-ups until fracture union. Then, radiographic evaluation was done at 3, 6 and 12 months. The average follow-up time was 26 months (range from 12 to 36 months) for group 1 and 25 months (range from 12 to 35 months) for group 2. The loss of the line of fracture through radiographic imaging of trabeculations or callus formation in the cortex on the anteroposterior and lateral radiographs, and clinically loss of sensitivity on fracture were considered fracture union.In the last controls, while the elbow was at 90 degrees of flexion, the amount of rotation of both forearms was measured by using the goniometer. In the functional evaluation, the system described by Grace and Eversmann and used to evaluate fracture union and forearm rotation was used [6]. Complete union of the fracture and providing at least $90 \%$ of the forearm rotation is considered excellent; union of the fracture and providing at least $80 \%$ of the forearm rotation is considered good; and union of the fracture and providing at least $60 \%$ of the forearm rotation is considered acceptable result. Non-union of the fracture or less than $60 \%$ forearm rotation was considered as a poor result. Patient satisfaction was evaluated by using the DASH (Disabilities of the Arm, Shoulder and Hand) method. In this scoring where the functional state of the upper extremity is questioned, while 0 points indicates a perfect extremity, 100 points indicate that the upper extremity is completely unusable. 


\section{Surgical Technique}

For both patient groups, surgery was started under general anesthesia or axillary block, in the supine position, following the necessary treatment and covering. Before the operation, patients received $1 \mathrm{~g}$ of cefazolin for prophylaxis. The plate was applied by inflating the tourniquet, the nail was applied without inflating the tourniquet under control.

Radial styloid and tuberositas radii were determined for radius in patients undergoing osteosynthesis with plate. Between the two, along the fracture line, the incision from the volar was carried out along the fracture line (Henry approach). After the incision was made, the lateral cutaneous nerve of the forearm was isolated and preserved in the superficial adipose tissue. The incision was continued until fascia. The fascia incision was made at the ulnar end of the brachioradial muscle. The brachioradialis muscle was moved and lifted. Dissection was continued by preserving the radial artery and radial nerve. Radius was exposed. For distal extending fractures, the place where the pronator muscle was held was dissected from the shaft and the fracture was exposed. For the proximal fractures, the radial sensory nerve was followed up to the point where it bifurcated with the posterior interosseous nerve and the supinator muscle was dissected from the ulnar side. After the fracture reduction was done with reduction clamps, a $3.5 \mathrm{~mm}$ locked compression plate was placed.

Olecranon and ulna styloid were determined for ulna. An incision was made along the line of fracture between the two (posterior approach). The incision was deepened into the fascia. Ulna was seen distally between the extensor carpiulnaris and flexor carpiulnaris muscles, more proximally between the extensor carpiulnaris and ancaneus muscles. $3.5 \mathrm{~mm}$ locked compression plate was placed after reduction was carried out with reduction clamps.

First of all, screws close to the fracture were placed for both bones. Interfragmanter screws were placed in patients who were deemed necessary. Then, screws were placed on the proximal and distal sides of the fracture and fixation was completed. According to the type of fracture and severity of injury, the length of the plate to be used and the number of screws were determined, but as a general principle, 3 screws were placed on both sides of the fracture line. After the tourniquet was loosened and bleeding was checked, drains were placed in both surgical sites and the layers were closed according to the procedure (Fig. 1).

In patients with intramedullary locking nail, a 1 $\mathrm{cm}$ incision was made over olecronon while the elbow was at 90 degrees of flexion. Under the control of the scopy, $2 \mathrm{~mm} \mathrm{~K}$ wire was sent into the canal after closed fracture reduction. Then the channel entrance was carved up to $2 \mathrm{~cm}$ distance with a $6 \mathrm{~mm}$ reamer. The channel diameter was extended with hand carvers. The guide wire was left in the channel.

For Radius, while the forearm was in prone position, a $2 \mathrm{~cm}$ incision was made by the radial side of the Lister tubercle. The entrance was made under the extensor carpiraldias brevis tendon at a distance of 5 $\mathrm{mm}$ from the joint surface. Afterwards, $2 \mathrm{~mm} \mathrm{~K}$ wire was sent into the canal after closed reduction of radius
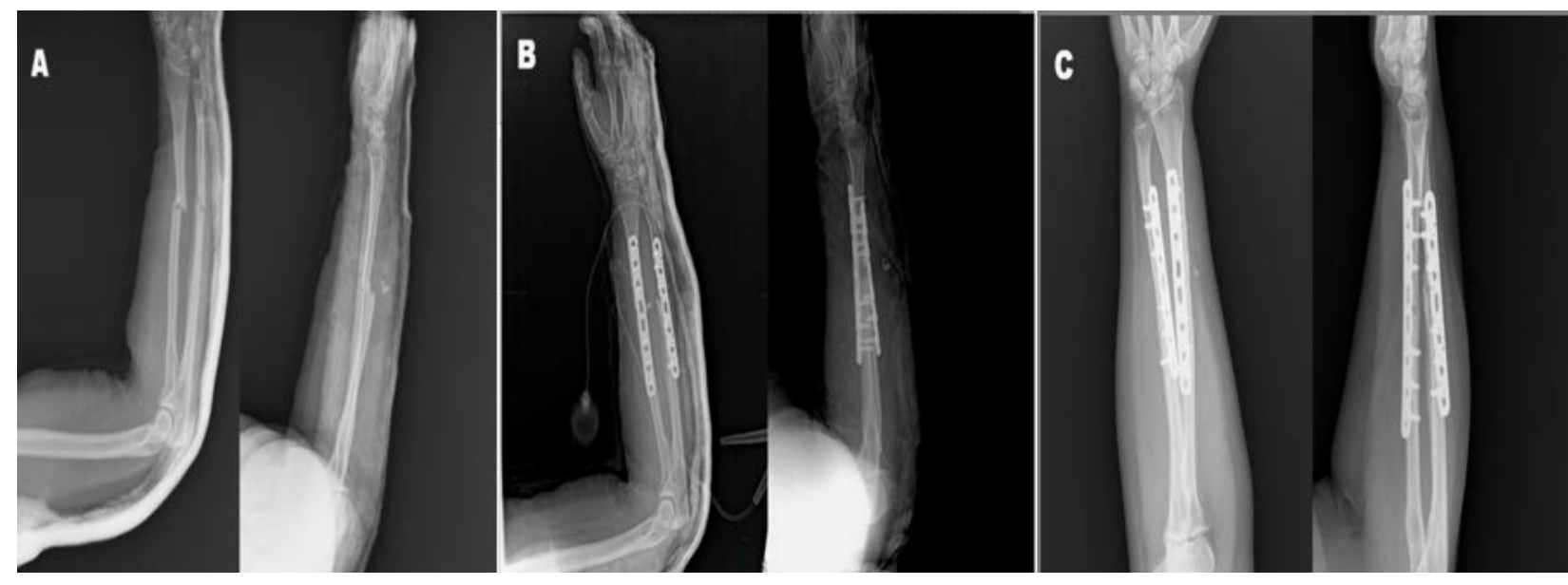

Fig. 1. Plate osteosynthesis. (A) Preoperative radiograms; (B) Postoperative radiograms; (C) Follow-up radiograms taken at 12 th month. 

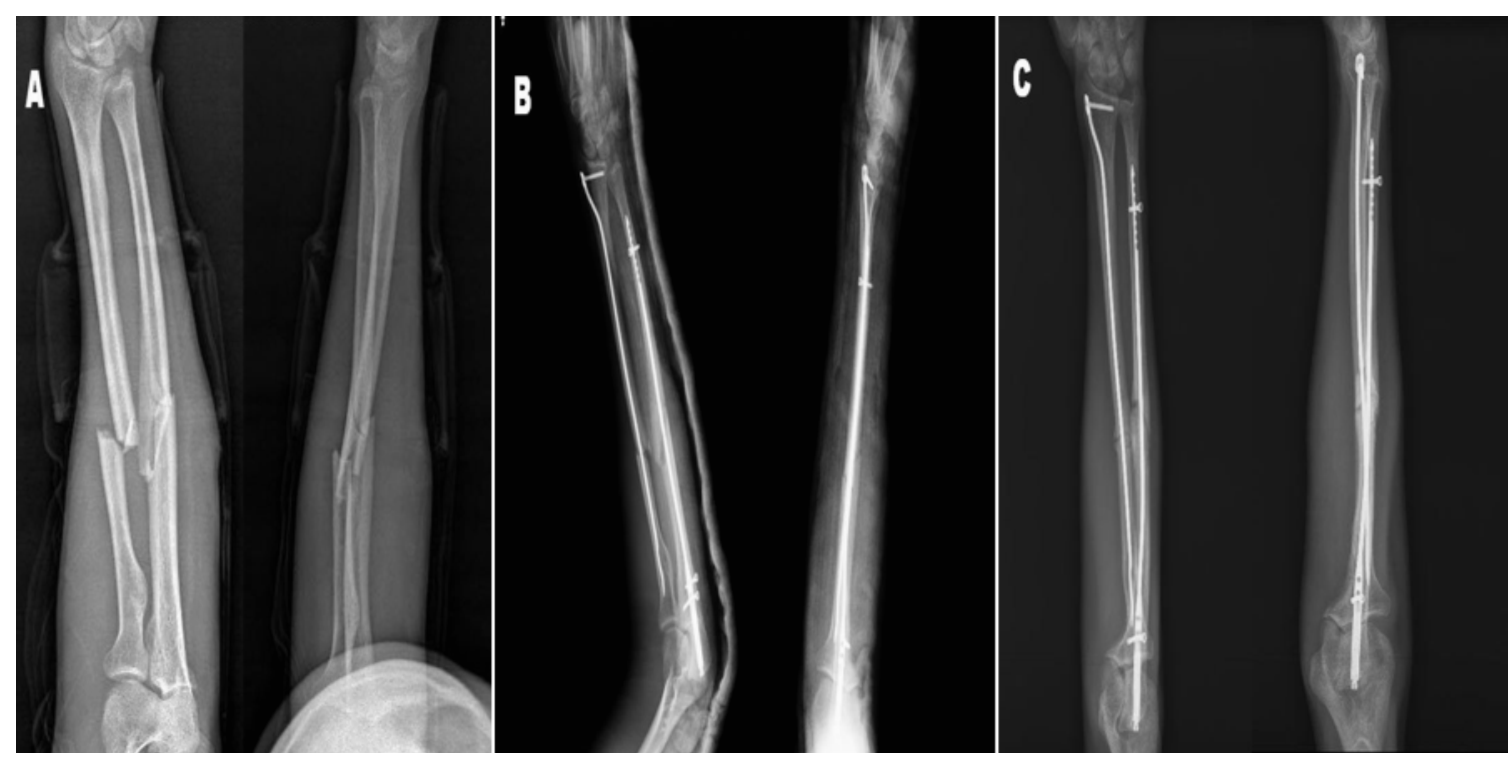

Fig. 2. Intramedullary locking nail. (A) Preoperative radiograms; (B) Postoperative radiograms; (C) Follow-up radiograms taken at 12th month.

fracture under the control of the scopy. Then the channel entrance was carved up to $2 \mathrm{~cm}$ distance with a 6 $\mathrm{mm}$ reamer. The channel diameter was extended with hand carvers. The guide wire was left in the channel. Nails of suitable length and width for both bones were placed in the canal and guide wires were drawn. For both bones, the side close to the fastening apparatus was first locked with a fully grooved $2.7 \mathrm{~mm}$ self-tapping screw, then the static locking screw was not used in any patient after stability control (Fig. 2).

\section{Statistical Analysis}

Statistical analysis was performed by using chisquare and t-student tests using SPSS 21 version for

Table 1. Patient's medical information and demographic distribution

\begin{tabular}{lcc}
\hline & $\begin{array}{c}\text { Group 1 } \\
(\mathbf{n = 2 3 )}\end{array}$ & $\begin{array}{c}\text { Group 2 } \\
(\mathbf{n = 1 6 )}\end{array}$ \\
\hline Average age (years) (range) & $39.8(19-74)$ & $36.6(18-68)$ \\
Average follow-up (month) (range) & $26(12-36)$ & $25(12-35)$ \\
Fractured forearm, n (\%) & & \\
$\quad$ Right & $13(56.5)$ & $9(56.2)$ \\
$\quad$ Left & $10(43.4)$ & $7(43.7)$ \\
Gender distribution, n (\%) & & $5(31.2)$ \\
$\quad$ Female & $9(39.1)$ & $11(68.7)$ \\
$\quad$ Male & $14(60.8)$ & $3(18.7)$ \\
Trauma etiology, n (\%) & & $3(18.7)$ \\
$\quad$ Traffic accident & $3(13)$ & $2(12.5)$ \\
Sports injury & $3(13)$ & $8(50)$ \\
Work injury & $4(17.3)$ & $8(50)$ \\
Fall & $13(56.5)$ & $5(31.2)$ \\
AO/OTA fracture type, n (\%) & & $3(18.7)$ \\
$\quad$ A & $10(43.4)$ & $8(34.7)$ \\
B & $5(21.7)$ & \\
C
\end{tabular}

Group 1 = Plate osteosynthesis group; Group 2 = Intramedullary locking nail group, OTA = Orthopaedic Trauma Association 
Windows. Numerical variables were expressed as mean \pm standard deviation and categorical variables were expressed as mean percentages. A $p$ value $<0.05$ was considered as statistically significant.

\section{RESULTS}

While the union duration in group 1 was 12.3 weeks (8-18 weeks), the union duration in group 2 was 12 weeks (9-16 weeks). Grace-Eversmann evaluation and DASH score statistical analysis are given in Table 2. There was no statistical difference in terms of union durations $(p>0.05)$. In Group 1, according to the Grace-Eversmann evaluation, $19(82.6 \%)$ patients had excellent and good results, three (13.1\%) patients had acceptable results, and 1 patient (4.3\%) had poor results. Forearm pronation of the patient with poor results was less than $60 \%$ but his bone union was complete. In group 1, the average DASH score was found to be 15.04 (range 3-28). In Group 2's GraceEversmann evaluation, excellent and good results were obtained from 13 patients $(81.3 \%)$ and acceptable results from three patients $(18.7 \%)$. Average DASH score was found to be 14.6 (range 2-34). When Grace-Eversmann criteria and DASH values were compared, no significant difference was found between the two groups $(p>0.05)$. In group 1, two patients developed superficial infections; both patients were treated with one week of parenteral antibiotics followed by one week of oral antibiotics. Deep infection was not observed in either group.Implants were removed in 3 patients in group 1 and 1 patient in group 1 after union. Vascular nerve injury, tendon injury, radioulnar synostosis, and compartment syn- drome were not observed in any patient.

\section{DISCUSSION}

There is consensus that the treatment of adult forearm double diaphyseal fractures is surgical. The results of these fractures with insufficient implants or conservative treatment led to high complication rates [7]. The traditional surgical method is open reduction and fixation with plate [8].As the treatment complications with plate developed, alternative treatment methods were constantly sought in the historical treatment process [9]. Intramedullary application was first performed in 1913 by using K wire and Steinmann nails ( $1^{\text {st }}$ generation) [10]. However, the necessary rotational stability was not achieved with these materials and it caused high non-union rates. The first nail design considering the forearm anatomy was made in 1959 ( $2^{\text {nd }}$ generation) [11]. However, since these nails did not have mechanisms to prevent locking and rotation, a union rate as good as plate could not be achieved.Despite this, changes in nail design continued and $3^{\text {rd }}$ generation nails which are locking mechanisms that also provide the rotational stability we use todaywere produced.

Anatomical or close reduction is obtained in fractures where osteosynthesis is applied with plate. However, impaired fracture hematoma and periosteal integrity are factors that may have negative effects on union [3]. During the surgical intervention, it is expected that there will be more bleeding than nail application. The risk of future fractures increases due to cortical atrophy occurring in the screw application areas. Cosmetic problems related to the surgical approach and more soft tissue damage are other unde-

Table 2. Statistical analysis: Union period, DASH score and Grace-Eversmann ratio

\begin{tabular}{lccc}
\hline & $\begin{array}{c}\text { Grup 1 } \\
(\mathbf{n = 2 3 )}\end{array}$ & $\begin{array}{c}\text { Grup 2 } \\
(\mathbf{n = 1 6 )}\end{array}$ & p value \\
\hline $\begin{array}{l}\text { Union Period (weeks) } \\
\text { (mean } \pm \text { SD) }\end{array}$ & $12.3 \pm 2.72$ & $12.0 \pm 2.19$ & 0.710 \\
$\begin{array}{l}\text { DASH Score } \\
\text { (mean } \pm \text { SD) }\end{array}$ & $15.04 \pm 6.05$ & $14.6 \pm 7.84$ & 0.850 \\
$\begin{array}{l}\text { Grace-Eversmann Ratio } \\
\text { (Perfect/Acceptable/Poor) }\end{array}$ & $19 / 3 / 1$ & $13 / 3 / 0$ & 0.640 \\
\hline
\end{tabular}

Group 1 = Plate osteosynthesis group; Group 2 = Intramedullary locking nail group, $\mathrm{SD}=$ standard deviation 
sirable aspects of plate osteosynthesis. Intramedullary locking nail causes less bleeding and less soft tissue damage. Cosmetically, it provides superiority to osteosynthesis with plate. However, in nail applications, ensuring proper rotation and anatomical reduction can be more difficult thanosteosynthesis with plate [4]. Also, exposure to more radiation is one of the disadvantages of nail application [12].

Anderson et al. [13] treated 330 forearm fractures of 258 patients by using compression plates and achieved $96.3 \%$ union in ulna fractures and $97.8 \%$ in radius fractures.In other studies, union rates have been reported between $87 \%$ and $98 \%$ [14]. Kose et al. [15, 16] reported that they achieved $100 \%$ union in all cases with intramedullary locking nail. Visna et al. [17] reported that 78 patients had union in the treatment of 118 forearm fractures, while Gao et al. [18] achieved nail union in all 18 patients. In our study, rates of union with plate and rates of union with nail were similar, and union was achieved in all patients. Anderson et al. [13] achieved a union at an average of 7.4 weeks in patients with open reduction and plate screw fixation. Stevens et al. [14] observed union in their forearm fractures for an average of 22 weeks in patients using dynamic compression plates, and 33 weeks in patients who used locked compression plates. Gao et al. [18] who used intramedullary locking nail in the treatment reported that closed fractures united within an average of 10 weeks and open fractures within 14 weeks. In addition, in the studies comparing nail and plate applications; the average union duration with plate was found to be 10 weeks by Lee et al. [19] , 11.1 weeks by Kim et al. [21], 14 weeks by Özkaya et al. [22], and 13.1 weeks by Köse et al. [20]. In the same studies, the average union duration with nail was found to be 14 weeks by Lee $e t$ al. [19], 13.1 weeks by Kim et al. [21], 10 weeks by Özkaya et al. [22], and 10.8 weeks by Köse et al. [20]. In our study, the duration of union with plate was found to be 12.3 weeks, and the duration of union with nail was found to be 12 weeks.

Another criterion we compared in our study is the DASH (The Disabilities of the Arm, Schoulder and Hand) scores between both groups [23]. The average DASH score in patients who were treated with plate was found to be 9.8 by Köse et al. [20], 15.3 by Lee et al. [19], 7.1 by Kim et al. [21], and 15 by Özkaya et al. [22]. In the same studies, the average DASH score in patients who were treated with nail was found to be 18.3 by Köse et al. [20], 12.8 by Lee et al. [19], 15.1 by Kim et al. [21], and 13 by Özkaya et al. [22]. In our study, the fact that the average DASH value was 15 in the plate group and 14.6 in the nail group, and that the results were close to each other made us consider that there is not any difference between the two techniques in terms of patient satisfaction provided that it was performed according to the technique. Another method in functional evaluation is the system described by Grace and Eversmann, in which fracture union and forearm rotation are evaluated. In this staging system, complete union of the fracture and providing at least $90 \%$ of the forearm rotation is considered excellent; union of the fracture and providing at least $80 \%$ of the forearm rotation is considered good; and union of the fracture and providing at least $60 \%$ of the forearm rotation is considered acceptable result.Non-union of the fracture or less than $60 \%$ forearm rotation was considered as a poor result. As a result, when both our study and other studies are evaluated through Grace Eversmann evaluation, the similarity of the results between the plate and nail application is remarkable.

If intramedullary locking nail are not chosen in proper length and diameter, complications may develop during surgery. Incompatibility of nail diameter and canal width can lead to rotational movements in cases where the length of the nail is short, and if the length of the nail is long, the fracture may break more [5]. Careful planning is essential before surgery. An iatrogenic bone injury was not observed in patients who underwent surgery in our clinic. Iatrogenic posterior interosseous nerve injury is rarely seen in forearm surgical treatment. It has been reported that this risk can be minimized especially in nail operations by keeping the proximal locking screw of the radial nail at least $30 \mathrm{~mm}$ from the radius head and keeping the forearm in neutral rotation. As the radius fracture approaches to proximal in patients who receive plate, more attention must be paid in terms of nerve damage [24]. In our study, attention was paid to these issues in patients using both plate and locked nails, and therefore no iatrogenic posterior interosseous nerve injury was observed. The disadvantage is that the duration of union is longer than plate 
osteosynthesis and more limited allowance for mobilization until bridge callus is seen in the fracture line. However, the use of a mini-incision, the peeling of the periosteum is the greatest advantage of the locked intramedullary nail when it is necessary to remove it again with a mini-incision [25].

\section{CONCLUSION}

In our study comparing two techniques used in the treatment of forearm fractures in adults, close results were obtained with both techniques in terms of patient satisfaction and functional evaluation. Therefore, we think that both techniques can be used in the treatment of forearm fractures in adults, provided that the rules are followed.

\section{Conflict of interest}

The author disclosed no conflict of interest during the preparation or publication of this manuscript.

\section{Financing}

The authors disclosed that they did not receive any grant during conduction or writing of this study.

\section{REFERENCES}

1. Markolf KL, Lamey D, Yang S, Meals R, Hotchkiss R. Radioulnar load-sharing in the forearm. A study in cadavera. J Bone Joint Surg Am 1998;80:879-88.

2. Abe S, Murase T, Oka K, Shigi A, Tanaka H, Yoshikawa H. In vivo three-dimensional analysis of malunited forearm diaphyseal fractures with forearm rotational restriction. J Bone Joint Surg Am 2018;100:e113.

3. Özbal R, Tezer M, Koçkesen TC, Özturk İ, Kuzgun Ü. Selection of osteosynthesis material in the surgical treatment of adult forearm diaphyseal fractures. Acta Orthop Traumatol Turc 2000;34:164-9.

4. Lee SK, Kim YH, Kim SM, Choy WS. A comparative study of three different surgical methods for both-forearm-bone fractures in adults. Acta Orthop Belg 2019;85:305-16.

5. Crenshaw AH Jr. Fractures of shoulder, arm and forearm. In: Canale ST, Daugherty K, Jones L, Azar FM, Beaty JH, Calandruccio JH, et al. editors. Campbell's operative orthopaedics. 10th ed. St. Louis: Mosby; 2003. p. 2985-3069.

6. Grace TG, Eversmann WW Jr. Forearm fractures: Tteatment by rigid fixation with early motion. J. Bone and Joint Surg 1980;62:433-8.

7. Boussakri H, Elibrahimi A, Bachiri M, Elidrissi M, Shimi M,
Elmrini A. Nonunion of fractures of the ulna and radius diaphyses: clinical and radiological results of surgical treatment. Malays Orthop J 2016;10:27-34.

8. Tabor OB Jr, Bosse MJ, Sims SH, Kellam JF. Iatrogenic posterior interosseous nerveinjury: is transosseous static locked nailing of the radius feasible? J OrthopTrauma 1995;9:427-9. 9. Behnke NM, Redjal HR, Nguyen VT, Zinar DM. Internal fixation of diaphyseal fractures of the forearm: a retrospective comparison of hybrid fixation versus dual plating. J Orthop Trauma 2012;26:611-6.

10. Bartoniček J, Kozanek M, Jupiter JB. History of operative treatment of forearm diaphyseal fractures. J Hand Surg Am 2014;39:335-42.

11. Sage FP. Medullary fixation of fractures of the forearm. A study of the medullary canal of the radius and a report of fifty fractures of the Radius treated with a prebent triangular nail. J Bone Joint Surg Am 1959;41-A:1489-516.

12. Groover MT, Hinkley JR, Gerow DE, Bamberger HB, Evans $\mathrm{J}$, Gazaille RE. The effect of metal instrumentation on patient and surgical team scatter radiation exposure using mini $\mathrm{C}$-arm in a simulated forearm fracture fixation model. J Am Acad Orthop Surg Glob Res Rev 2019;3:e089.

13. Anderson LD, Sisk D, Tooms RE, Park WI 3rd. Compression-plate fixation in acute diaphyseal fractures of the Radius and ulna. J Bone Joint Surg Am 1975;57:287-97.

14. Stevens CT, ten Duis HJ. Plate osteosynthesis of simple forearm fractures: LCP versus DC plates. Acta Orthop Belg 2008;74:180-3.

15. Kose A, Aydın A, Ezirmik N, Topal M, Can CE, Yılar S. Intramedullary nailing of adult isolated diaphyseal radius fractures. Ulus Travma Acil Cerrahi Derg 2016;22:184-91.

16. Kose A, Aydin A, Ezirmik N, Topal M, Can CE. Treatment of isolated ulnar fractures in adults with a new intramedullary nail. Minerva Ortop Traumatol 2015;66:123-31.

17. Visńa P, Beitl E, Pilny J, Cizmar I, Vlcek M, Kalvach J, et al. Interlocking nailing of forearm fractures. Acta Chir Belg 2008;108:333-8.

18. Gao H, Luo CF, Zhang CQ, Shi HP, Fan CY, Zen BF. Internal fixation of diaphyseal fractures of the forearm by interlocking intramedullary nail: short-term results in eighteen patients. J Orthop Trauma 2005;19:384-91.

19. Lee YH, Lee SK, Chung MS, Baek GH, Gong HS, Kim KH. Interlocking contoured intramedullary nail fixation for selected diaphyseal fractures of the forearm in adults. J Bone Joint Surg Am 2008;90:1891-8.

20. Köse A, Aydın A, Ezirmik N, Yıldırım ÖS. A comparison of the treatment results of open reduction internal fixation and intramedullary nailing in adult forearm diaphyseal fractures. Ulus Travma Acil Cerrahi Derg 2017;23:235-44.

21. Kim SB, Heo YM, Yi JW, Lee JB, Lim BG. Shaft fractures of both forearm bones: the outcomes of surgical treatment with plating only and combined plating and intramedullary nailing. Clin Orthop Surg 2015;7:282-90.

22. Ozkaya U, Kiliç A, Ozdoğan U, Beng K, Kabukçuoğlu Y. Comparison between locked intramedullary nailing and plate osteosynthesis in the management of adult forearm fractures. Acta Orthop Traumatol Turc 2009;43:14-20. 
23. Hudak PL, Amadio PC, Bombardier C. Development of an upper extremity outcome measure: the DASH (disabilities of the arm, shoulder and hand). [corrected]. The Upper Extremity Collaborative Group (UECG). Am J Ind Med 1996;29:602-8.

24. Bulstra LF, Schep NWL, van der Vlies CH. Posterior interosseous nerve palsy after closed proximal forearm fractures. Trauma Case Rep 2019;23:100240.

25. Moerman J, Lenaert A, De Coninck D, Haeck L, Verbeke S, Uyttendaele D, et al. Intramedullary fixation of forearm fractures in adults. Acta Orthop Belg 1996;62:34-40. 